\title{
Application of E-Learning Technologies in the Management of Secondary Schools in the Era of Emergency in Rivers State
}

Orji W. Uzochukwu ${ }^{1 *}$, Dr. Joy C. Nzok
$\begin{gathered}{ }^{1} \text { Department of Educational Management, F } \\ \text { Article History } \\ \text { Received: } 04.12 .2021 \\ \text { Accepted: } 11.01 .2022 \\ \text { Published: } 15.01 .2022 \\ \text { Journal homepage: } \\ \text { https://www.easpublisher.com }\end{gathered}$

\author{
um $^{1}$
}

Faculty of Education, University of Port Harcourt, Rivers State, Nigeria

\begin{abstract}
The study investigated application of e-learning technologies in the management of secondary schools in the era of emergency in Rivers State. Two research questions and two hypotheses tested at 0.05 level of significance guided the study. The study adopted descriptive design. The population of the study comprised all the 276 public senior secondary schools in Rivers State. A sample of 206 principals was drawn using simple random sampling technique. The instrument for data collection was titled 'Application of E-Learning Technologies in the Management of Secondary Schools in the Era of Emergency Questionnaire (AETMSSEEQ). The instrument was validated by an expert in Educational Management and two other experts in Measurement and Evaluation for internal consistency. Cronbach Alpha method was used to establish reliability index of the instrument at 0.82. Data collected was collated and analyzed using mean and standard deviation. The findings of the study showed that principals responded positively that the use of laptop and television can be applied in the management of secondary schools in the era of emergency. Furthermore, the study showed that a significant difference exists between the mean scores of male and female respondents on the ways the use of television can be applied in the management of secondary schools in the era of emergency. It was concluded that e-learning technologies can be used in the management of secondary schools in the era of emergency in Rivers State. Recommendations were made included that government should make adequate funds for provision of e-learning technologies (such as, WiFi, laptops, smartphones, tablets, etc.) and other logistical support that would strengthen seamless application of e-learning technologies in the management of in public secondary schools in the state.

Keywords: e-learning technologies, The instrument, Educational Management.
\end{abstract}

Copyright (C) 2022 The Author(s): This is an open-access article distributed under the terms of the Creative Commons Attribution 4.0 International License (CC BY-NC 4.0) which permits unrestricted use, distribution, and reproduction in any medium for non-commercial use provided the original author and source are credited.

\section{INTRODUCTION}

The Secondary School level of education is just a step immediately after the primary level of education. It is headed and managed by a principal. Management of secondary schools is the core responsibility of the principal. The principal who is in charge of the affairs of all activities in the school also takes the responsibility of preparing students for university education and for future leadership purposes. This is the reason why the principal was employed. Anything short of that means that the principal is probably not qualified and/or lacks the leadership qualities to lead the school aright. The principal's job description cuts across different areas of school leadership - ensuring that teachers and students carry out their functions properly and ensuring that the general well-being of the school system at all times. The principal is saddled with the responsibility of managing staff and students in all matters affecting the school. He or she is also charged with the responsibility of finding new ways of ensuring the continuation of teaching and learning in school, even during emergencies.

The principal's managerial qualities are essential for effective administration of the school especially during crisis. According to Abenga (1995), many organizational leaders, school administrators inclusive, adopt managerial styles which engender cooperation of staff through motivation to enhance staff work performance and productivity. In other words, the principal can be referred to a manager of the school system; he/she is responsible for the general administration of an organization or a group of staff (Ifediatu, 2017). A school manager for instance, needs to have interpersonal skills, technical and conceptual skills in order to organize and coordinate the operations of the school effectively, stimulate staff morale 
maximally, so that they may contribute positively to the attainment of education goals. Apparently, the ability of the principal to manage daunting situation and proffer reasonable solutions to delicate cases in school is dependent on the quality of skills and knowledge the school administrators have.

Principals are only in acting capacity, and thus represent the Ministry of Education at school level. According to Gaparayi et al., (2008), the school administration is different from that of enterprises due to its goal. However, like any other organization, the school needs means to run efficiently. These means are mainly of human, material, financial, legal and technological nature. The existence of these means is not enough in itself; there is a need to make a rational combination and utilization which fundamentally remains the responsibility of the principal. Hence, the principal is held accountable for effective management of the school even during emergencies such as Covid19 pandemic. Management in this context is the process of making strategic plans, setting organizational objectives, managing resources and deploying people and finances to achieve set objectives and measure results (Hissom, 2009). Management may be described as the coordination of all the resources of an organization through the process of planning, organizing, directing and control, in order to attain organizational goals (Ogbonna as cited in Osaat, 2020).

According to Save The Children (2009), emergency is any situation that poses considerable threat to public safety and health, which may be in form of apparent hazard and danger to a sizable number of people in a given community. The scholar further remarked that emergency may take the form of outbreak of diseases, war or a breakdown in security and essential services, which may result in loss of life, physical and mental injury and displacement. Emergency may be regarded as a normal phenomenon because no human being has the power to control time and season, either at both instance or separately. It is any activity that alters normal cause of nature. It could range from natural disaster such as earthquake, floods, pollution to other communal crisis such as cult activities, militancy, kidnapping, banditry, constant raiding of a location by hoodlums, explosions, terrorism and so on. A typical example of emergency is that which is being experienced in Borno State, one of the Northern States in Nigeria today. It is such a serious threat that, many families had to flee from their residence to neighbouring states and countries for safety. Many lives have been lost, many disfigured and wounded while others have lost their means of livelihood to the insurgency.

COVID-19 pandemic is current a global emergency that disrupted all economic activities around the world. Up till now, the world is racing against time develop effective vaccines to inoculate people from the mutating disease. It is known fact that educational system lost so much during peak of the crisis. As the third and fourth waves of the pandemic continues in some parts of Africa and the world, there is urgent need for education industry to rethink the means of managing education using technologies to bypass the limitations orchestrated by pandemic. The case of Africa may be viewed critical, as it has eaten into the fabrics of the nation's economy so deeply, leaving many confused. Hence, nobody, organization or nation has power over some emergencies and when they can occur. Because of the outbreak of COVID-19, emergency was declared in schools across the nation, resulting in a serious lag in the proper management and administration of many schools. Some of the deficiencies were manifested in the areas of poor decay in infrastructural facilities, staff turnover, incompetent teachers, poor reward management/mechanism/strategies, inability to meet global standard and poor academic performance of students, due to apparent lack of adoption of e-learning technologies in teaching and learning.

E-learning technologies may be referred to man-made devices created to aid teaching and learning. It is a $21^{\text {st }}$ century initiative with the aim of solving seemingly difficult tasks in a split of seconds. It was also created to reduce workload and time wastage in the performance of tasks in organizations. According to Usman and Igbozuruike (2019) e-learning stands for electronic learning, which simply means learning mediated by electronic technology. Most countries of the world have moved on with life and educational activities using electronic technologies. In education, elearning technologies have proven to be helpful during emergencies. E-learning may be referred to as a modern way of knowledge transmission of information through electronic devices within the context of education. . Elearning technologies is all kinds of electronic devices, media or technology such as radio, telephony, satellite broadcast, computers, the internet others devices that have assisted in different ways to enhance teaching and learning. The use of modern technologies in enhancing delivery of education is increasingly becoming a common phenomenon in educational institutions in developing countries (Mbwette, 2011; Moyo, 2003; Nihuka, 2011).

In e-learning particularly, there are useful electronic components that can be used and managed to conduct school management activities remotely during emergencies; some of them include desktop computer. According to the British English dictionary, desktop computers are electronic gadgets used in offices, schools, churches, etc. It is a programmed electronic device that performs mathematical calculations and logical operations, especially one that can process, store and retrieve large amount of data very quickly. Now especially, a small one can be for personal or home use, employed for manipulating text or graphics, accessing the internet or playing games or media. According to 
Adebisi (2013), a computer is an electronic device, operating under the control of instructions stored in its own memory. These instructions tell the machine what to do. The computer is capable of accepting data (input), processing data arithmetically and logically, producing output from the processing, and storing the results for future use. Most computers that sit on a desktop are called Personal Computers (PCs). People use computers in many ways; for business - computers are used to track inventories with bar codes and scanners, check the credit status of customers, and transfer funds electronically. A laptop is a portable computer that is small enough and light enough to be used on one's lap, but large enough to have an integrated keyboard. They can, in fact, perform like any desktop PC but have the advantage of being more readily integrated into management and classroom situations or learning activities. Principals can use laptop to prepare budgets, accounts, school time table, communicate with teachers and students and so on.

The technology offered by laptop can be used to teach and to learn, to create and to share. There are several advantages to using laptops in schools, but one of the most notable is the fact that they offer an alternative to traditional computer room scenarios. They can, in fact, perform like any desktop PC but have the advantage of being more readily integrated into classroom situations or learning activities. Roschelle et al. (2000) stated that access to laptop computers can change both how and what students learn, within as well as outside school boundaries. Other interesting use of laptop computers is the ability to enhance how children learn by supporting four fundamental characteristics of learning: (a) active engagement, (b) participation in groups, (c) frequent interaction and feedback, and (d) connections to real-world contexts.

Television is another form of e-learning tools that enjoys large viewership/audience in Nigeria. Burns as cited in Ukaigwe (2020) report showed that about 75 million households in Sub-Sahara have access to television. It blends moving pictures with sound to produce a communication experience exhibited on the screen. It uses sound to explain the visuals presented on the screen. It utilizes high-current electromagnetic spectrum transmitters to communicate signals to connected television receivers, like satellite dish, and antenna (Landabidea \& Loos, 2015). Television uses the movement of images in a unique way or pattern to express thoughts and feelings in an exciting and appealing manner. Television is defined by the BBC English Dictionary (1992) as the system of pictures and distance, so that people can receive them on a television set. From the definition, radio and television were a common phenomenon; they use electrical signals in sending out their messages. Researches have also shown that some students are visual learners; their comprehension and learning is accelerated by seeing the object or example of what their teacher is explaining (Saglik, \& Ozturk, 2001).

TV-assisted instruction can be used to assist learners in this category. With proper and rich instruction design and lesson plan, the teacher can display the object of discussion on the screen while continuing his/her explanation from behind the screen. This will help the students to have a clearer look at the concerned object in order to comprehend its colour, structure, and dimensions, for enhanced retention. Misra (2010) explained that television posses with it the following capabilities of video, audio and motion, is a strong, modern mass medium of transferring information to mass audience in current age. Misra maintained that there are several uses of television, and one of such is the educational use of television, which is a prominent one. This could be traced as the skilful public broadcasters of many countries routinely provide locally-relevant and explicitly educational television, often to support subjects such as mathematics or science in schools, or the distance education courses of open universities and teacher training centres.

\section{Statement of the Problem}

School management is a critical aspect of effective school. However, in situations whereby school managerial resources are lacking, school management will be adversely affected. The problem of school management in Nigeria is not only related to principals' performance deficiencies, but also infrastructural and facility inadequacies. This has been laid bare by the ongoing pandemic, which has revealed the decays status of school facilities and manpower inadequacies required to manage school effectively in this era of Covid-19 pandemic. Secondary schools in Rivers State were on total lockdown during the peak of Covid-19 crisis, and when relative normalcy was restored to some extent, it was discovered that general academic activities had suffered a lag and students were at the receiving end of the effects. For instance, some schools which have had to shut down within this period did not have internet, generator or regular power supply, functional desktop computers, laptops and other gadgets that aid school management functions relative to communication.

These made principals to appear as though they have lost grip of school system in this era of the Covid-19 pandemic. School principals are expected to coordinate certain school operations remotely in line with social distance rules. However, the current situation suggests that many secondary schools do not have relevant e-learning technologies. Even those that have some of the devices that aid school managerial functions seem to lack technical skill required to manipulate the facilities to aid school management. This adversely affects the management of schools in Rivers State. The application of e-learning technology can go a long way in addressing these challenges of school management in the era of emergency. The 
problem of this study therefore bothers on answering this basic question; can the application of e-learning technologies help in addressing the challenges of secondary school management in the era of emergency in Rivers State? This is the problem the study.

\section{Research Questions}

The following research questions guided the study:

1. In what ways can the use of laptop be applied in the management of secondary schools in the era of emergency in Rivers State?

2. What are the ways the use of television can be applied in the management of secondary schools in the era of emergency in Rivers State?

\section{Hypotheses}

The following null hypotheses were tested at 0.05 alpha level of significance:

1. There is no significant difference in the mean scores of male and female principals on the ways the use of laptop can be applied in the management of secondary schools in the era of emergency in Rivers State.

2. There is no significant difference in the mean scores of principals in urban and rural area on the ways the use of television can be applied in the management of secondary schools in the era of emergency in Rivers State.

\section{MeTHODOLOGY}

The study design of the study was descriptive. The population of the study was 276 principals (185 males and 91 females) distributed across the 23 Local Government Areas in Rivers State. The sample size was 206 principals, comprising 129 males and 77 female principals serving in public secondary schools in Rivers State. The simple random sampling technique was used to draw the sample. The instrument used to generate data was a self-structured 10-item questionnaire titled 'Application of E-Learning Technologies in the Management of Secondary Schools in the Era of Emergency Questionnaire (AETMSSEEQ). It was divided into two sections, namely, Section $\mathrm{A}$ and Section B. Section A contained items seeking data on demographic variables of the respondents, while section B contained items assessing the two variables investigated in this study. Test re-test was used to establish the reliability co-efficient of the instrument at 0.80 . The modified four-point Likert-type rating scale of Strongly Agree (4 points), Agree (3 points), Disagree ( 2 points) and Strongly Disagree (1 point) was used to code responses. Items that scored $\mathrm{x} \geq 2.50$ criteria were accepted whereas those below the criteria were deemed rejected by the respondents. The research questions were answered using mean statistics, while the hypotheses were tested with z-test at 0.05 significance level.

\section{RESULTS AND DISCUSSION}

Research Question One: In what ways can the use of laptop be applied in the management of secondary schools in the era of emergency in Rivers State?

Table 1: Mean $(\bar{x})$ and standard deviation of respondents on the ways the use of laptop can be applied in the management of secondary schools in the era of emergency in Rivers State

\begin{tabular}{|c|c|c|c|c|c|c|c|c|c|}
\hline \multirow[t]{2}{*}{$\mathbf{S} / \mathbf{N}$} & \multirow[t]{2}{*}{ Items Description } & \multicolumn{4}{|c|}{ Male $(\mathbf{N}=129)$} & \multicolumn{4}{|c|}{ Female $(N=77)$} \\
\hline & & $\bar{X}_{1}$ & $\mathrm{SD}_{1}$ & $\begin{array}{l}\text { Rank } \\
\text { Order }\end{array}$ & Remarks & $\bar{X}_{2}$ & $\mathrm{SD}_{2}$ & $\begin{array}{l}\text { Rank } \\
\text { Order }\end{array}$ & Remarks \\
\hline 1. & $\begin{array}{l}\text { Laptops help school principals to type official } \\
\text { documents. }\end{array}$ & 3.60 & 0.49 & $3^{\text {rd }}$ & Agree & 3.45 & 0.50 & $4^{\text {th }}$ & Agree \\
\hline 2. & $\begin{array}{l}\text { Laptops facilitate online audio-visual communication } \\
\text { between principals and remote school staff during } \\
\text { emergency. }\end{array}$ & 3.59 & 0.49 & $2^{\text {nd }}$ & Agree & 3.59 & 0.49 & $2^{\text {nd }}$ & Agree \\
\hline 3. & $\begin{array}{l}\text { Internet enabled laptops are used to organize school } \\
\text { management meetings during emergency }\end{array}$ & 3.82 & 0.38 & $1^{\mathrm{st}}$ & Agree & 3.54 & 0.49 & $3^{\text {rd }}$ & Agree \\
\hline 4. & $\begin{array}{l}\text { School managers use laptops to prepare school } \\
\text { budget. }\end{array}$ & 3.41 & 0.81 & $4^{\text {th }}$ & Agree & 3.78 & 0.41 & $1^{\mathrm{st}}$ & Agree \\
\hline 5. & $\begin{array}{l}\text { Laptops enable principals to organize school files } \\
\text { digitally for remote access of school data. }\end{array}$ & 3.38 & 0.66 & $5^{\text {th }}$ & Agree & 3.42 & 0.73 & $5^{\text {th }}$ & Agree \\
\hline & Average Mean/Standard Deviation & 3.56 & 0.57 & & & 3.56 & 0.53 & & \\
\hline
\end{tabular}

In table 1 above, all the items were agreed by the respondents, resulting in average high mean scores of 3.56 for male and 3.56 for female, and thus establishes that all the agreed items are ways the use of laptop can be applied in the management of secondary schools in the era of emergency. Furthermore, the average standard deviation of male (0.57) and female (0.53) principals suggest moderate dispersion of data, and thus implies that the respondents' opinions are moderately united in their views.

Research Question Two: What are the ways the use of television can be applied in the management of secondary schools in the era of emergency in Rivers State? 
Table 2: Mean $\left(\bar{x}^{\bar{x}}\right)$ and standard deviation of respondents on the ways the use of television be applied in the management of secondary schools in the era of emergency in Rivers State

\begin{tabular}{|c|c|c|c|c|c|c|c|c|c|}
\hline \multirow[t]{2}{*}{$\mathbf{S} / \mathbf{N}$} & \multirow[t]{2}{*}{ Items Description } & \multicolumn{4}{|c|}{ Rural $(\mathbf{N}=126)$} & \multicolumn{4}{|c|}{ Urban $(\mathbf{N}=\mathbf{8 0})$} \\
\hline & & $\overline{\bar{X}}_{1}$ & $\mathrm{SD}_{1}$ & $\begin{array}{l}\text { Rank } \\
\text { Order }\end{array}$ & Remarks & $\bar{X}_{2}$ & $\mathrm{SD}_{2}$ & $\begin{array}{l}\text { Rank } \\
\text { Order }\end{array}$ & Remarks \\
\hline 6 & $\begin{array}{l}\text { School principals use television to } \\
\text { disseminate information to students. }\end{array}$ & 3.39 & 0.61 & $3^{\text {rd }}$ & Agree & 3.41 & 0.75 & $4^{\text {th }}$ & Agree \\
\hline 7 & $\begin{array}{l}\text { School principals use television to } \\
\text { disseminate information to teachers. }\end{array}$ & 3.19 & 0.70 & $5^{\text {th }}$ & Agree & 3.86 & 0.35 & $1^{\mathrm{st}}$ & Agree \\
\hline 8 & $\begin{array}{l}\text { School managers schedule teachers for } \\
\text { instructing distant students through } \\
\text { television broadcast. }\end{array}$ & 3.26 & 0.63 & $4^{\text {th }}$ & Agree & 3.67 & 0.47 & $2^{\text {nd }}$ & Agree \\
\hline 9 & $\begin{array}{l}\text { School principals take advantage of } \\
\text { television to advertise school services. }\end{array}$ & 3.63 & 0.45 & $1^{\mathrm{st}}$ & Agree & 3.53 & 0.50 & $3^{\text {rd }}$ & Agree \\
\hline 10 & $\begin{array}{l}\text { Broadcast of educational television } \\
\text { programmes helps principals to acquire } \\
\text { knowledge on ways of managing schools. }\end{array}$ & 3.49 & 0.54 & $2^{\text {nd }}$ & Agree & 3.86 & 0.35 & $1^{\mathrm{st}}$ & Agree \\
\hline & Average Mean/Standard Deviation & 3.42 & 0.59 & & & 3.64 & 0.49 & & \\
\hline
\end{tabular}

In table 2 above, all the items were agreed by the respondents, resulting in average high mean scores of 3.42 and 3.64 for principals in rural and urban areas respectively, and this implies that the agreed items constituted ways the use of television can be applied to the management of secondary schools in the era of emergency. The average standard deviations of the two categories of respondents $(0.59 ; 0.49)$ are moderate, and thus suggest that the data of both categories of the respondents are moderately concentrated.

\section{Test of Hypotheses}

Ho: : There is no significant difference in the mean scores of male and female principals on the ways the use of laptop can be applied in the management of secondary schools in the era of emergency in Rivers State.

Table 3: z-test Analysis on the difference between the mean rating scores of male and female principals on the ways the use of laptop can be applied in the management of secondary schools in the era of emergency in Rivers State

\begin{tabular}{|c|c|c|c|c|c|c|c|}
\hline Category & $\mathbf{N}$ & $\bar{X}$ & SD & Df & z-cal & z-crit. & Remarks \\
\hline Male & 129 & 3.65 & 0.57 & & & & Not significant \\
\hline Female & 77 & 3.56 & 0.53 & 204 & 1.16 & \pm 1.96 & $\begin{array}{l}\mathrm{Ho}_{1} \text {, not rejected } \\
\text { (z-cal. < z-crit.) }\end{array}$ \\
\hline
\end{tabular}

Table 3 showed that the male principals have mean and standard deviation scores of 3.65 and 0.57 , while female principals have mean and standard deviation scores of 3.56 and 0.52 respectively. With 204 degrees of freedom and alpha level of 0.05 , the $\mathrm{z}$ calculated value was ascertained at 1.16 . Since the $\mathrm{z}$ calculated value of 1.16 is lower than the $\mathrm{z}$-critical value of 1.96, the above stated null hypothesis is accepted. By implication, no significant difference exists between the mean scores of male and female principals on the ways the use of laptop can be applied in the management of secondary schools in the era of emergency.

$\mathbf{H o}_{2}$ : There is no significant difference in the mean scores of principals in urban and rural area on the ways the use of television can be applied in the management of secondary schools in the era of emergency in Rivers State.

Table 4: z-test analysis on the difference between the mean rating scores of principals in urban and rural on the ways the use of television can be applied in the management of secondary schools in the era of emergency in

\section{Rivers State}

\begin{tabular}{|c|c|c|c|c|c|c|c|}
\hline Category & $\mathbf{N}$ & $\bar{X}$ & SD & Df & Z-cal & z-crit. & Remarks \\
\hline Urban & 80 & 3.42 & 0.59 & & & & Significant \\
\hline Rural & 126 & 3.64 & 0.49 & 204 & 2.89 & 96 & $\begin{array}{l}\mathrm{Ho}_{2} \text { rejected } \\
\text { (z-cal.> z-crit.) }\end{array}$ \\
\hline
\end{tabular}

Table 4 showed that the mean and standard deviation scores of principals in rural areas 3.42 and 0.59 , while their urban counterparts have mean and standard deviation scores of 3.64 and 0.49 respectively. With 204 degrees of freedom and alpha level of 0.05 , the $\mathrm{z}$-calculated value was ascertained at 2.89 . Since the $\mathrm{z}$-calculated value of 2.89 is higher than the $\mathrm{z}$-critical value of 1.96, the above stated null hypothesis is rejected. By implication, a significant difference exists between the mean scores of principals in rural and urban areas on the ways the use of television can be applied in the management of secondary schools in the era of emergency. 


\section{DiSCUSSION OF FINDINGS}

Ways the use of television can be applied in the management of secondary schools in the era of emergency in Rivers State

Use of laptop in the management of secondary schools in the era of emergency

The findings revealed that, the respondents agreed to the use of laptop as one of the e-learning technologies in the management of secondary schools in the era of emergency in Rivers State, since it can be used to carry out administrative functions such as typing official documents, audio-visual communication, management meetings, prepare school budget, and to access digital files remote school data. The reason for these may be related to the diverse utility of laptop in processing documents and files, among other functionalities of the device. The findings were in line with the outcome of the study by Roschelle et al., (2000) which stated that access to laptop computers can change both how and what students learn, within as well as outside school boundaries. Other interesting uses of laptop computers are the ability to enhance how children learn by supporting four fundamental characteristics of learning: (a) active engagement, (b) participation in groups, (c) frequent interaction and feedback, and (d) connections to real-world contexts. This was supported by Rockman (2003), who observed that that the use of laptop computers can also change what students learn by providing exposure to some new ideas and experiences that otherwise would be inaccessible. These rare opportunities are particularly useful in developing the higher-order skills of critical thinking, analysis, and inquiry that are necessary for success in the 21 st century educational system.

This study found out that no significant difference exists between the mean scores of male and female principals on the ways the use of laptop can be applied in the management of secondary schools in the era of emergency. Corroborating this finding, Donahue et al (2001) observed that laptop computer is created to provide real improvements, that by so doing, teachers need to use technology to support knowledge-building and discourse rather than reinforce traditional ways of teaching where students act primarily as receivers of information. When laptops are connected to a digital projector, teachers or students can easily incorporate presentations or multimedia resources into lessons. This is especially useful in a second-level environment where teachers may frequently move from class to class, although classroom management issues do need to be considered in such situations. While elaborating the functionalities of laptop, Donahue et al, further observed that laptop provide flexibility in timetabling rooms, as it is a viable option where space is an issue. The scholar continued that mobility feature of laptop provide significant facility to individual work, adding that staff can carry out their functions from different location using internet enable laptop.
Use of television in the management of secondary schools in the era of emergency

The findings revealed that, the respondents agreed to the use of television as one of the e-learning technologies in the management of secondary schools in the era of emergency in Rivers State, since it can be used to carry out administrative functions such as dissemination of information, instructing distant students through broadcast, advertise the school and help principals acquire required knowledge for school management. The reason for these findings be connected to the fact that television helps to broadcast wireless audio-visual signals to people's homes so that without physical contact. The findings of the study was in line with the study by Olumorin et al., (2018) which reported that Nigeria Television Authority (NTA) Ogbomoso broadcast educational content regularly, most of which centres on educational programmes geared towards enlightening the masses on issues concerning environmental degradation, pollution and their adverse effects on human life. Content producers can thus infuse interactive component to programme broadcast to rouse and sustain the interest of learners and thus focus their attention properly on topic understudy. The subject or topic of a lesson has to be properly condensed and embodied into the programmes, in such a way that the learners are carried along.

Also, Saglik and Ozturk (2001) observed that television has continued to be the most important medium for conveying information, news and culture in its broadest sense. It is regarded as universal in its availability and it is still free at the point of use to its viewers. The researchers are of the view that like television, Internet can also play significant educational role. Misra (2010) explained that television posses with it the following capabilities of video, audio and motion, is a strong, modern mass medium of transferring information to mass audience in current age.

\section{CONCLUSION}

Based on the findings, this study concludes that application of e-learning technologies such as laptops and televisions can be used effectively in the management of secondary schools in the era of emergency in Rivers State.

\section{RECOMMENDATIONS}

Based on the conclusion of the study, the following recommendations were highlighted:

1. Government should make adequate funds for provision of e-learning technologies (such as, Wi$\mathrm{Fi}$, laptops, smartphones, tablets, etc.) and other logistical support that would strengthen seamless application of e-learning technologies in the management of in public secondary schools in the state.

2. Government should invest in communication infrastructures to boost connectivity and reliability 
of networks so that school managers can coordinate school activities from remote locations using elearning technologies such as television, cable and terrestrial networks.

3. School managers/principals should adopt elearning technologies in the delivery of instructions, since it can be used for other administrative duties to the benefit of the school.

\section{REFERENCES}

- Abenga, F. M. (1995). Principles and practice of school administration in Nigeria. Onaivi Printing and Publishing Press

- Adebisi, J. A. (2013). Fundamentals of computer studies. Expert solution consult.

- BBC English Dictionary: A Dictionary for the World, (1992). Harper- Collins Publisher.

- Donahue, P. L., Finnegan, P. L., Lutkus, A. D., Allen, N. L., \& Campbell, J. R. (2001). The nation's report card: Fourth-grade reading 2000. National Center for Education Statistics Office of Educational Research and Improvement, NCES 2001-499.

- Gaparayi, A., Nsengumukiza, A., \& Rutali, G. (2008). School management: Training manual for secondary school head teachers. Mineduc School Management.

- Hissom, A. (2009). Introduction to management technology.

http://www.amyhissom.com/MyWritings/Manage ment.pdf.

- Ifediatu, N.M. (2017). Principalship in the $21^{\text {st }}$ century: The Nigerian experience. In W.A. Amaewhule, N.M. Abraham \& J. D. Asodike (ed.). School business management: theoretical \& practical approach. Pearl publishers international Ltd.

- Landabidea Urresti, X., \& Loos, E. F. (2015). Contemporary meanings and experiences of television in the digital age. International Journal of Digital Television, 6 (1), 43-60. http://dx.doi.org/10.1386/jdtv.6.1.43

- Mbwette, T. S. A. (2011). Speech of the vice chancellor of The Open University of Tanzania to students and staff during his visit to Tanga, Moshi, Arusha, Mbeya, Njombe, Iringa, Morogoro and Cost regional centres, 20th $-29^{\text {th }}$ December, 2011. (Retried from http://www.out.ac.tz/announcements/general/Speec $\mathrm{h} \% 20$ of $\% 20$ the $\% 20$ Vice $\%$

20chancellor $\% 20$ to $\% 20$ staff $\% 20$ and $\% 20$ students $\%$ 20in\%20Tanga, \%20Moshi $\% 20$ Arusha, \%20Mbeya,\%20Njombe,\%20Iringa,\% 20Morogoro\%20a.pdf
- Misra, P. K. (2010). Internet for educational television: An opportunity or threat.

- Moyo, S. (2003). Distance learning and virtual education for higher education in Africa: Evaluation of options and strategies. African and Asian Studies, 2(4), 497-519.

- Nihuka, K. A. (2011). Collaborative course design to support implementation of e-learning by instructors. $\mathrm{PhD}$ thesis. University of Twente, Enschede-Netherlands.

http://doc.utwente.nl/78096/1/thesis_K_Nihuka.pdf

- Osaat, D. S. (2020). Managing secondary schools in the face of COVID-19 in Nigeria: Issues, challenges and way forward. In C.M. Uche, S.O. Oluwuo \& N.M Abraham (eds.). In management of education in the era of COVID-19, social distancing and social connections: Challenges and prospects in Nigeria. University of Port Harcourt Press.

- Rockman, S. (2003). Learning from laptops: Threshold. San Francisco: Author. Available: http://www.rockman.com/publications.

- Roschelle, J., Pea, R. D., Hoadley, C. M., Gordin, D. G., \& Means, B. (2000). Changing how and what children learn in school with computer-based technologies. The Future of Children, 10(2), 76101.

- Roschelle, J., Pea, R. D., Hoadley, C. M., Gordin, D. G., \& Means, B. (2000). Changing how and what children learn in school with computer-based technologies. The Future of Children, 10(2), 76101.

- Saglik, M., \& Ozturk, S. (2001). Television as an educational technology: using television at Open Education Faculty, Anadolu University. Turkish Online Journal of Distance Education-TOJDE, 2(1), https://tojde.anadolu.edu.tr/tojde3/pdf/6.pdf

- Save The Children. (2009). "Re-Write the Future: Education in Emergencies." www.ineesite.org/uploads/documents/store/Educati on_in_emergencies_ReWrite_the_

- Ukaigwe, P. C. (2020). Managing secondary education in the era of COVID_19: Trends, challenges, and prospects in Nigeria. In C.M. Uche, S.O. Oluwuo, \& N.M Abraham (eds.). In management of education in the era of COVID-19, social distancing and social connections: Challenges and prospects in Nigeria. University of Port Harcourt Press.

- Usman, H., \& Igbozuruike, I. U. (2019). Integration of e-learning in secondary education and the imperatives of planning for sustainable improvement in students' achievement in PortHarcourt Metropolis. Knowledge Review, 38(1), 101-109.

Cite This Article: Orji W. Uzochukwu \& Joy C. Nzokurum (2022). Application of E-Learning Technologies in the Management of Secondary Schools in the Era of Emergency in Rivers State. EAS J PsycholBehavSci, 4(1), 1-7. 